\title{
As novas tecnologias da informação e comunicação entre a promessa de liberdade e o risco de controle total: estudo da jurisprudência do sistema interamericano de direitos humanos
}

\author{
The New Technologies of Information \\ and Communication Between the Freedom Promise \\ and the Total Control Risk: Study of the Jurisprudence \\ of the Inter-American Human Rights System
}

\author{
Jânia Maria LOPEZ SALDANHA* \\ Márcio MORAIS BRUM** \\ Rafaela DA CRUZ MELLO****
}

\begin{abstract}
SUMÁRIO: I. Introdução. II. As novas tecnologias da informação e a promessa de liberdade total. III. Do big brother ao círculo: a era do acesso e os riscos de controle total. IV. Conclusão. V. Referências.
\end{abstract}

\footnotetext{
* Doutora em Dereito. Realiza estudos de pós-doutorado junto ao IHEJ — Institut dês Hautes études sur La Justice quanto também junto à Université Sorbonne Paris II- Panthéon-Assas. Bolsista CAPES Proc-Bex 2417146. Professora Associada do PPG em Dereito da UFSM. Advogada. Email: janiasaldanha@gmail.com.

** Mestrando em Dereito pero Programa de Pós-Graduação em Dereito da Universidade Federal de Santa Maria. Advogado. Membro da Comissão de Direitos Humanos da Ordem dos Advogados do Brasil, Subseção Santa Maria. Email: marciombrum@gmail.com.

*** Mestrando em Dereito pelo Programa de Pós-Graduação em Direito da Universidade Federal de Santa Maria. Advogada, Membro da Comissão de Dereitos Humanos da Ordem dos Advogados do Brasil, Subseção Santa Maria.Email: rafaelcruzmello@gmail.com.
}

Artículo recibido el 9 de julio de 2015 Aprobado para publicación el 31 de agosto de 2015 
Resumo: O artigo tem como objetivo analisar dois fenômenos da sociedade da informação: a liberdade total e o controle total das comunicações e conteúdos de usuários da rede. Diante disso, almeja-se responder de que maneira o Sistema Interamericano de Proteção dos Direitos Humanos trabalha com a dialética entre liberdade e vigilância por meio das novas tecnologias de informação e comunicação. Utiliza-se o método dialético de abordagem e o método de procedimento comparativo. Ao fim, conclui-se que, ao defender a ideia de regulação normativa das formas de controle sobre comunicações e dados, o Sistema Interamericano acredita na eficácia e autonomia do direito frente ao poder e aos interesses de outros sistemas sociais que se revelem contrários aos direitos humanos.

Palavras-chave: liberdade, controle, novas tecnologias, Sistema Interamericano de Direitos Humanos.

ABSTRACT: The article aims to analyze two phenomena of the information society: the total freedom and total control of communications and network users content. Therefore, we aimed to answer how the Inter-American System of Human Rights Protection works with the dialectic between freedom and surveillance through new technologies of information and communication. We use the dialectical method of approach and the method of comparative procedure. In the end, it is concluded that, in defending the idea of normative regulation of the forms of control over communications and data, the inter-American system believes in the effectiveness and independence of the right front of the power and the interests of other social systems as may be contrary to rights humans.

Key words: freedom, control, new technologies, Inter-American System of Human Rights Protection.

RESUMÉ: L'article vise à analyser deux phénomènes de la société de l'information: la liberté totale et le contrôle total des communications et des utilisateurs du réseau de contenu. Par consequece, nous avons cherché à répondre à la façon dont le système interaméricain de protection des droits de l'homme travaille avec la dialectique entre la liberté et de la surveillance par le biais de nouvelles technologies de l'information et de la communication. Nous utilisons la méthode dialectique de l'approche et la méthode de la procédure comparative. En fin de compte, il est conclu que, dans la défense de l' idée d'une régulation normative des formes de contrôle des communications et des données, le système inter-américain croit en l'efficacité et l'indépendance de l'avant droit de la puissance et les intérêts des autres systèmes sociaux que peut être contraire aux droits les humains.

Mot-Clés: liberté, contrôle, les nouvelles technologies, Système interaméricain des droits humanes. 


\section{INTRODUÇÃO}

O século XXI pode até agora ser considerado o ápice do vislumbre da passagem de uma sociedade industrial a uma sociedade informacional. Esta última marcada, sobretudo, pela expansão do domínio de sistemas técnicos e pela transformação do espaço em ciberespaço, trazendo expectativas, ilusões e poucas certezas.

Assim como o ciberespaço permite a abertura de um campo imenso de possibilidades políticas e culturais, de discussões pluralistas, de possibilidades de tomada conjunta e de modo democrático de decisões, evidenciando um espectro de liberdade advinda da possibilidade de acesso à rede, ele também possui o lado de risco de um controle total. Este, tendo em vista que o desenvolvimento de softwares e novas formas de regulação, sobretudo da internet, permitem o controle de comunicações e de dados pessoais dos usuários da rede, tanto por empresas privadas — com o intuito de mercantilização do conteúdo destes dados - quanto pelos próprios Estados, com a finalidade de recuperar parte do poder que lhes fora subtraído com a eclosão da internet como fenômeno global.

Neste contexto, o presente trabalho tem como problema os seguintes questionamentos: de que modo o Sistema Interamericano de Proteção dos Direitos Humanos trabalha com a dialética entre liberdade e vigilância por meio das novas tecnologias de informação e comunicação, e que saídas aponta para impedir a marcha rumo a uma sociedade de controle total? $\mathrm{Na}$ busca de respostas para tais indagações, a investigação emprega o método dialético de abordagem, opondo as teses doutrinárias e jurisprudenciais que sustentam a ampliação da liberdade humana na rede às teses que chamam atenção para os riscos de controle total acarretados pelas novas tecnologias informacionais.

Visando a uma abordagem adequada do problema, o artigo está dividido em dois grandes capítulos. Na primeira parte (Parte 1) são expostas as promessas de liberdade total advindas das novas tecnologias, com enfoque para a universalização do acesso como uma das formas primordiais para o exercício da liberdade na sociedade da informação (1.1). Na sequencia, é trabalhada a jurisprudência do Sistema Interamericano sob os vieses de acesso e liberdade na América (1.2). 
Esta revista forma parte del acervo de la Biblioteca Jurídica Virtual del Instituto de Investigaciones Jurídicas de la UNAM

A segunda parte (Parte 2), por sua vez, almeja colocar em confronto com a premissa de liberdade total, as ideias de controle e de vigilância na rede (2.1), para, na sequência, trabalhar com o posicionamento do Sistema Interamericano acerca dos riscos de controle total, bem como as propostas para redução desses riscos (2.2).

\section{AS NOVAS TECNOLOGIAS DA INFORMAÇÃO E A PROMESSA DE LIBERDADE TOTAL}

Para alguns pensadores contemporâneos, a exemplo de Pierre Lévy, o uso maciço das técnicas digitais de acesso à informação e de comunicação interativa pode ser muito útil a todos os cidadãos, na medida em que as "ágoras virtuais" ajudem a melhorar a elaboração de questões, a negociação e a tomada de decisões coletivas. Lévy' afirma que "o uso socialmente mais rico da informática comunicacional consiste, sem dúvida, em fornecer aos grupos humanos os meios de reunir suas forças mentais para constituir coletivos inteligentes ${ }^{2}$ e dar vida a uma democracia em tempo real".

Para o autor, mais comunicação implicará naturalmente mais liberdade, visto que "a capacidade de comunicar e de circular tem uma estreita relação com o desenvolvimento da liberdade”. A partir dessas premissas, o autor desenvolve o conceito de ciberdemocracia, entendida como ápice da história das conquistas sociais, num sentido de aceleração do processo de emancipação humana. O Ciberespaço, lugar das relações em tempo real e da difusão nunca antes vista de informação/comunicação, é o ambiente no qual pode se desenvolver a desejada ciberdemocracia. ${ }^{3}$

Assim, as "comunidades inteligentes", ${ }^{4}$ a "governação eletrônica", as "ágoras virtuais”, seriam a nova realidade desse novo espaço de ampliação

1 Lévy, Pierre, A Inteligência Coletiva: por uma antropologia do ciberespaço, 9.ed., São Paulo, Edições Loyola, 2014, p. 64.

$2 \mathrm{O}$ autor define inteligência coletiva como "uma inteligência distribuída por toda parte, incessantemente valorizada, coordenada em tempo real, que resulta em uma mobilização efetiva das competências". Nessa ótica, o aperfeiçoamento da inteligência coletiva será o produto e o sentido da evolução cultural. Ibidem, p. 18.

3 Lévy, Pierre, Ciberdemocracia, Lisboa, Instituto Piaget, 2002, p. 23.

4 Interessante salientar que Lévy prefere o termo "civilização da inteligência coletiva" em detrimento do mais usual "sociedade da informação". Lévy, Pierre, A inteligência..., cit., p. 175. 
democrática e virtual onde a participação, a cooperação e o livre acesso à informação contribuiriam para soluções coletivas aos mais variados problemas sociais. Segundo Lévy, as TIC's aumentam também a possibilidade de participação e controle popular das empresas multinacionais, e o mercado poderá ser transformado de "ditador antidemocrático" para "instrumento de pilotagem", uma espécie de sistema eleitoral permanente no qual todo e qualquer ato de compra representará um voto ${ }^{5}$.

A visão otimista de Pierre Lévy é compartilhada por André Volkmer, ${ }^{6}$ para quem "na história da humanidade, o poder nunca esteve tão à mão do indivíduo" e "a internet, provavelmente, diminuirá muito o radicalismo e aumentará o respeito aos direitos humanos, à ética e à moral”. ${ }^{7}$ No mesmo sentido, Gonçalves ${ }^{8}$ afirma que as possibilidades técnicas de comunicação e de acesso à informação permitiriam desfrutar mais plenamente os direitos e liberdades contemplados pelos regimes liberais/democráticos.

A questão sociológica da atualidade, portanto, diz respeito às metamorfoses que o advento das novas tecnologias da informação e comunicação geram na própria noção de cidadania. Esta, entendida como poder de participação livre na vida política, confere ao cidadão um protagonismo ativo na determinação não só da política estatal, mas na influência em todas as esferas de decisão política com poder de definir questões de interesse geral da população. ${ }^{9}$

Sem dúvida, uma forma de estimular e possibilitar a participação política encontra-se no aproveitamento dos recursos tecnológicos informacionais. Surge a possibilidade de conjugar a democracia representativa tradicional com experiências de democracia direta participativa. Conforme observa Pérez Luño, ${ }^{10}$ a teledemocracia aparece hoje como um signo revitalizador do exercício da cidadania que, de acordo com as exigências da participação política na era tecnológica, contextualiza a titularidade, tutela e exercício da cidadania.

5 Ibidem, p. 149.

6 Volkmer, André, A democracia na era digital. In: Instituto De Estudos Empresariais. Liberdade na era digital. Porto Alegre, IEE, 2011, p. 90-109.

7 Ibidem, p. 104.

8 Gonçalves, Maria Eduarda, Direito da informação: novos direitos e formas de regulação na sociedade da informação, Coimbra, Almedina, 2003, p. 31.

9 Pérez Luño, Antonio-Enrique, Ciberciudadani@o ciudadani@.com?, Barcelona, Gedisa, 2004.

10 Idem. 
Esta revista forma parte del acervo de la Biblioteca Jurídica Virtual del Instituto de Investigaciones Jurídicas de la UNAM

No entanto, para que a teledemocracia possa garantir decisões políticas responsáveis pressupõe-se o oferecimento de condições adequadas de informação e reflexão, de modo que o pluralismo informativo, o livre acesso e a livre circulação de informações são elementos-chave contra a manipulação e o monopólio informativo. Afinal, na sociedade em que vivemos, informação é poder e esse poder se torna decisivo quando converte informação dispersa e parcial em informação de massa e organizada. ${ }^{11}$

Por isso, Pérez Luño ${ }^{12}$ adverte que se a teledemocracia, por um lado, pode dar origem a um novo tipo de cidadania (uma "cibercidadania") mais autêntico, profundo e adequado aos parâmetros tecnológicos, por outro lado, sem a garantia do devido acesso à informação, pode criar uma indesejável “cidadania.com” em que o titular poderá ser transformado em mero sujeito passivo da manipulação dos poderes públicos e privados.

Esse risco de degeneração da democracia encontra-se estreitamente ligado ao problema da desigualdade que se tem estabelecido no ciberespaço, na medida em que a internet cria novas formas de desigualdade entre "inforricos" e "infopobres" ao estabelecer discriminações graves no acesso e utilização de informações entre o Norte e o Sul. Chama atenção, por exemplo, o fato de haver mais linhas telefônicas na Ilha de Manhattan, Nova York, do que em toda a África, sabendo-se que sem linhas não se pode acessar à internet. ${ }^{13}$

Frente a essa problemática, esta primeira parte do trabalho se propõe a abordar o imperativo de universalização do acesso às novas tecnologias da informação e comunicação como condição para uma liberdade humana substancial na rede (1.1), bem como, na sequência, verificar as normas e orientações jurisprudenciais do Sistema Interamericano de Direitos Humanos no que diz respeito ao tema (1.2).

\section{Universalização do acesso: condição para a liberdade substancial}

Ao recusar o Prêmio Nobel de Literatura, em 1964, Jean-Paul Sartre afirmou que "[liberdade] é uma palavra que se presta a numerosas interpre-

11 Idem.

12 Idem.

13 Ramonet, Ignacio, ¡Nos han robado una esperanza!, S/d. Disponível em http://pendiente demigracion.ucm.es/info/uepei/noshanrobado.html. Acesso em 9 mai. 2015. 
tações. No ocidente, se fala de liberdade num sentido geral. Entendo a liberdade de uma forma mais concreta, que consiste no direito de ter mais de um par de sapatos e de comer pão menos duro". Na época, ainda não se falava em revolução cibernética ou, ao menos, não tanto quanto nas décadas seguintes, mas hoje a afirmação de Sartre poderia ser atualizada para incluir no conceito de liberdade o direito fundamental de acesso às tecnologias da informação e comunicação.

Diariamente, bilhões de pessoas acessam as redes para comercializar, gerenciar negócios, efetuar transações financeiras, comunicar-se através de redes sociais, estudar, acessar revistas, jornais e informações em vídeo, dentre uma infinidade de outras possibilidades proporcionadas pela rede. Neste cenário mundial, será livre aquele que não acessa e domina as novas tecnologias, ainda que por opção pessoal?

São compreensíveis as razões dos que optam por permanecer distante das TICs, em razão dos riscos inerentes. Afinal, conforme já alertava Milton Santos $^{14}$, os objetos técnicos são controlados pelos centros de comando e não podem ser utilizados pelos atores não hegemônicos senão de forma passiva, o que implica no risco de dominação pelos detentores da expertise informacional.

Paradoxalmente, permanecer fora da internet e ignorar o modo de funcionamento das tecnologias informacionais acarreta uma diminuição exponencial da possibilidade de exercer alguma influência: "com essa atitude, opta-se por não ser influente. É a mesma coisa no caso dos celulares: você pode escolher não ter um celular, mas isso reduz a sua influência. Não é um bom caminho". ${ }^{15}$

Se a afirmação anterior é verdadeira, o não acesso às redes ocasiona uma limitação da liberdade do sujeito, inclusive para exercer a crítica e a resistência à própria dominação tecnológica, porquanto a resistência demanda uso e domínio sobre o modo de funcionamento da tecnologia. Scott Lash chega a afirmar que a crítica da sociedade da informação deve ser sem transcendentais, pois não há um “eu pensante” fora da informação. Ou seja,

14 Santos, Milton, Técnica, Espaço, Tempo: globalização e meio técnico-científico-informacional, 5a. ed., São Paulo, Editora da Universidade de São Paulo, 2013.

15 Assange, Julian, Cypherpunks: liberdade e o futuro da internet, tradução Cristina Yamagami, São Paulo, Boitempo, 2013, p. 68. 
Esta revista forma parte del acervo de la Biblioteca Jurídica Virtual del Instituto de Investigaciones Jurídicas de la UNAM

a crítica só pode ser feita em um plano imanente de atores conectados em interfaces por máquinas. ${ }^{16}$

$\mathrm{Na}$ sociedade da informação, portanto, o domínio das tecnologias informacionais dá vantagem considerável aos grupos que fazem um uso adequado delas. Se na sociedade industrial do século passado as desigualdades provinham basicamente da exploração do trabalho pelo capital, na era da informação a desigualdade é produto da exclusão dos fluxos informacionais e comunicacionais. Isso gera uma rede de elites desenraizadas que transita pelos "espaços genéricos" de performatividade - aeroportos, aviões, grandes lojas de marca, parques de diversão, internet. ${ }^{17}$

Surge, então, uma nova forma de estratificação social, relacionada à proteção da propriedade intelectual e ao direito de acesso aos espaços genéricos. Estes, para serem acessados, exigem dinheiro e geralmente são bastante caros. Ocorre que os usuários das interfaces tecnológicas e ocupantes dos espaços genéricos terão um papel cada vez mais decisivo na política. ${ }^{18}$

Como apontado por Santos ${ }^{19}$ e Mattelart,${ }^{20} \mathrm{O}$ acesso às tecnologias divide o mundo entre lentos e rápidos: grupos, instituições e indivíduos convivem juntos, mas não praticam os mesmos tempos, pois os ritmos de cada qual não são os mesmos. Ao lado das temporalidades hegemonizadas, dos lentos, há as temporalidades hegemônicas, praticadas pelos rápidos, cenário onde a rapidez se torna argumento de autoridade.

Portanto, na era da informação, o acesso universal às ferramentas tecnológicas de comunicação e informação é basilar para o exercício da democracia. Por “acesso" compreende-se não só a viabilização da infraestrutura e das condições econômicas da acessibilidade, mas a disponibilização de instrumentos que permitam o desenvolvimento da capacidade dos sujeitos para o uso das funcionalidades e para a solução de problemas relacionados às TICs, ${ }^{21}$ Além disso, não basta o acesso a serviços de baixa qualidade, pois os recursos de voz e vídeo são os que mais atribuem valor à Internet, razão

16 Lash, Scott, Crítica de la información, tradução Horácio Pons, Buenos Aires, Amorrotu, 2005, p. 33.

17 Ibidem, pp. 51 e 52.

18 Idem.

19 Santos, Milton, op. cit.

20 Mattelart, Armand, História das teorias da comunicação, São Paulo, Loyola, 1999.

21 Merli, Daniel et al., "Exclusão digital no Brasil e em países emergentes: um panorama da primeira década do século XXI", in Silva, Sivaldo P. e Biondi, Antonio (orgs.), Caminhos 
Esta revista forma parte del acervo de la Biblioteca Jurídica Virtual del Instituto de Investigaciones Jurídicas de la UNAM

pela qual a banda larga já se tornou sinônimo daquilo que chamamos de "internet". ${ }^{22}$

No cenário atual, grupos privados do gozo da agilidade e eficiência da banda larga passam a ser vítimas de uma nova exclusão digital: a da velocidade dos fluxos de dados. Esse é um problema que extrapola a esfera individual, porquanto a universalização do acesso à banda larga é considerada um importante fator de desenvolvimento nacional. Como advertem Silva e Biondi, ${ }^{23} \mathrm{o}$ acesso à banda larga tornou-se uma fronteira estratégica para o desenvolvimento das nações, o que explica o fato de vários países dedicarem esforços e recursos para implementar seus planos e estratégias nacionais, visando a universalização da banda larga a todos os seus cidadãos.

Conforme relatório do Banco Mundial, de 2009, o aumento de dez pontos percentuais nas conexões de banda larga de um país corresponde a um crescimento adicional de 1,3\% do seu Produto Interno Bruto. ${ }^{24}$ Portanto, a universalização da banda larga é condição estratégica que repercute no desenvolvimento social, econômico e cultural das nações. Por conta disso, já no começo dos anos 2000, países como Canadá e Coreia do Sul iniciaram suas políticas de universalização de banda larga, de modo que atualmente os governos dessas nações discutem como vencer a barreira de $2 \%$ ou $3 \%$ da população ainda sem acesso, ou de como universalizar super velocidades e de tornar a internet ubíqua - com presença direta e constante no dia-a-dia das pessoas, em suas casas e ambientes de convívio social. ${ }^{25}$

Em países como o Brasil, todavia, as políticas de universalização/massificação ainda estão dando seus passos iniciais. No país, mais da metade da população continua sem acesso à banda larga, utilizando serviços de baixa

para a universalização da internet banda larga: experiências internacionais e desafios brasileiros, São Paulo, Intervozes, 2012.

22 Possebon, Samuel, "Prefácio", Silva, Sivaldo P.; Biondi, Antonio (orgs.), in Caminhos para a universalização da internet banda larga: experiências internacionais e desafios brasileiros, São Paulo, Intervozes, 2012.

23 Silva, Sivaldo P. e Biondi, Antonio, "Políticas públicas e regulação do acesso à Internet banda larga: diretrizes para o caso brasileiro sob a luz das experiências internacionais", in Silva, Sivaldo P. e Biondi, Antonio (orgs.), Caminhos para a universalização da internet banda larga: experiências internacionais e desafios brasileiros, São Paulo, Intervozes, 2012.

24 World Bank, Information and Communications for Development 2009: Extending Reach and Increasing Impact, Washington DC, World Bank, 2009.

25 Possebon, Samuel, op. cit. 
Esta revista forma parte del acervo de la Biblioteca Jurídica Virtual del Instituto de Investigaciones Jurídicas de la UNAM

qualidade e custo elevado. ${ }^{26}$ Essa é a realidade dos substratos da população de grandes centros urbanos com baixo poder aquisitivo, moradores de cidades pequenas e médias e, sobretudo, das áreas mais afastadas, como a zona rural. ${ }^{27}$

Ciente disso, em 2010, o governo federal lançou o Programa Nacional de Banda Larga (PNBL), visando implementar uma política estratégica com os objetivos de melhorar a infraestrutura, ampliar o acesso, reduzir o custo dos serviços e incentivar a competitividade entre as empresas prestadoras. Trata-se de uma importante iniciativa que já apresenta resultados práticos positivos na ampliação do acesso, mas que contém distorções relacionadas à competitividade, subsídios, garantia de direito, estratégia de longo prazo e controle de qualidade, que comprometem a materialização dos objetivos. ${ }^{28}$

De acordo com o Relatório de avaliação do PNBL, produzido pelo Senado brasileiro, em dezembro de 2014, em 2009 havia 15 milhões de domicílios conectados à internet. Desses, cerca de 10 milhões utilizavam acesso por banda larga fixa. Já em 2013, o número de domicílios conectados à internet havia subido para 27,2 milhões, sendo 18 milhões por banda larga fixa. ${ }^{29} \mathrm{~A}$ análise dos números demonstra um considerável avanço no uso da banda larga fixa, com crescimento de mais de $80 \%$ na quantidade de acessos. Porém, a meta fixada para 2014 esteve longe de ser alcançada. Com base nos dados disponíveis e em estimativas formuladas pela Consultoria Legislativa do Senado, calcula-se que exista no Brasil um hiato digital cor-

26 Valente, Jonas C. L., "Regulação do Acesso à Internet no Mundo: modelos, direitos e desafios”, in Silva, Sivaldo P. e Biondi, Antonio (orgs.), Caminhos para a universalização da internet banda larga: experiências internacionais e desafios brasileiros, São Paulo: Intervozes, 2012.

27 Um dos problemas centrais para a universalização da banda larga no Brasil é que os serviços são fornecidos através de um mercado concentrado em grandes corporações que operam dominando a prestação do serviço em determinadas regiões ou nichos de atuação, sob um modelo empresarial de telecomunicações (Biondi, Antonio et al., "Programa Nacional de Banda Larga no Brasil: características e desafios”, in Silva, Sivaldo P. e Biondi, Antonio (orgs.), op. cit.). Esta realidade demonstra a incapacidade do mercado, por si só, aumentar os índices de penetração da banda larga domiciliar de modo satisfatório, o que requer a interferência do Estado na solução do problema. Afinal, na gestão dos bens comuns da humanidade (meio-ambiente, saúde, educação, cultura) o serviço público necessita prevalecer sobre os mecanismos do mercado. Mattelart, Armand, op. cit.

28 Biondi, Antonio, op.cit.

29 Senado Federal, Relatório de Avaliação do Programa Nacional de Banda Larga (PNBL). Dez. 2014. Disponível em: http://www.senado.gov.br/noticias/especiais/politicas-publicas-pnbl/. Acesso em 17 jun. 2015. 
Esta revista forma parte del acervo de la Biblioteca Jurídica Virtual del Instituto de Investigaciones Jurídicas de la UNAM

respondente a 38,4 milhões de famílias, o que corresponde a mais de 2/3 (dois terços) das famílias brasileiras. ${ }^{30}$

Inobstante o gap digital, em 2014 o Brasil tornou-se o país detentor de uma das legislações mais avançadas do planeta sobre regulação da internet: o Marco Civil da Internet. A lei, que já tem servido de modelo para outros países $^{31}$, estabelece princípios, garantias, direitos e deveres para o uso da internet no Brasil e determina diretrizes para atuação da União, dos Estados, do Distrito Federal e dos Municípios em relação à matéria.

$\mathrm{O}$ art. $3^{\circ}$ da Lei institui que a disciplina do uso da internet no Brasil tem como princípios, dentre outros, a garantia da liberdade de expressão, comunicação e manifestação do pensamento, e a preservação da estabilidade, segurança e funcionalidade da rede, por meio de medidas técnicas compatíveis com os padrões internacionais e pelo estímulo ao uso de boas práticas. Por sua vez, o art. $4^{\circ}$ afirma que a disciplina do uso da internet no Brasil tem por objetivo a promoção do direito de acesso à internet a todos; do acesso à informação, ao conhecimento e à participação na vida cultural e na condução dos assuntos públicos; da inovação e do fomento à ampla difusão de novas tecnologias e modelos de uso e acesso; e da adesão a padrões tecnológicos abertos que permitam a comunicação, a acessibilidade e a interoperabilidade entre aplicações e bases de dados.

A interpretação conjunta dos princípios e objetivos do Marco Civil, em especial daqueles elencados nos artigos $3^{\circ}$ e $4^{\circ}$, à luz dos princípios da Constituição Federal brasileira, ratifica o reconhecimento do direito de acesso universal à internet, assim como o imperativo de que a qualidade dos serviços seja compatível com os padrões internacionais de estabilidade, segurança e funcionalidade da rede. ${ }^{32}$

30 Idem.

31 Carvalho, Maria Augusta, "Marco Civil brasileiro para a Internet já é copiado no exterior”, Consultor Jurídico (CONJUR), publicado em 02 set. 2014. Disponível em: http: / / www. conjur.com.br/2014-set-02/marco-civil-brasileiro-internet-copiado-exterior. Acesso em 01 set. 2015.

32 Portanto, o gap digital hoje existente no país não decorre da falta de normas jurídicas que reconheçam o direito de acesso e a necessidade de universalização da banda larga, mas provavelmente da fragilidade das políticas públicas até agora implementadas e da insuficiência dos recursos financeiros destinados à ampliação e melhoria da infraestrutura das redes digitais. 
Esta revista forma parte del acervo de la Biblioteca Jurídica Virtual del Instituto de Investigaciones Jurídicas de la UNAM

Mas, para além da normatização interna, adquirem especial relevância as normas e jurisprudência dos organismos internacionais de defesa dos direitos humanos. Como destaca Gonçalves, ${ }^{33}$ no parâmetro da sociedade informacional, em que redes de comunicação ligam diferentes sujeitos, deve haver o reconhecimento de fontes normativas alternativas às estatais/ nacionais ou, até mesmo, de "um direito global que responda a necessidades específicas da Internet como espaço transnacional”.

De fato, com a mundialização do direito, há o estabelecimento de redes de comunicação e influência recíproca entre as instituições jurisdicionais, seja por vinculação normativa obrigatória ou pelo diálogo espontâneo entre tribunais e demais instituições públicas. E neste contexto, o direito internacional dos direitos humanos cumpre o importante papel de fixação de estacas progressivamente mais protetoras aos direitos do homem, na medida da sua independência em relação ao poder dos Estados.

Os países latino-americanos, particularmente, integram o Sistema Interamericano de Proteção dos Direitos Humanos (SIDH), cujas normas em especial a Convenção Americana sobre Direitos Humanos (CADH) - e jurisprudência são de observância obrigatória pelos Estados-membros, por força do que estabelecem os artigos 1o., 2o. e 62 da Convenção. Atualmente, um dos organismos que compõem o SIDH, a Comissão Interamericana de Direitos Humanos (CIDH), vem construindo jurisprudência própria sobre os temas da liberdade de expressão e acesso à informação, relacionados ao uso das novas tecnologias da informação e comunicação.

\section{Visões do sistema interamericano de proteção dos direitos humanos sob a perspectiva do acesso às tecnologias na sociedade informacional}

Até o momento, não há manifestações da Corte Interamericana de Direitos Humanos (Corte IDH) sobre o direito de acesso às tecnologias da informação e comunicação. Por se tratar de um direito que transcende a esfera individual das liberdades civis e políticas, adentrando no domínio econômico, social e cultural (DESC), sua justiciabilidade encontra algumas limitações relacionadas à competência da Corte Interamericana, ${ }^{34}$ o que

33 Gonçalves, Maria Eduarda, op. cit.

34 A categoria dos direitos econômicos, sociais e culturais não está na lista dos direitos com aplicabilidade imediata e individualmente demandáveis previstos na Convenção Ame- 
Esta revista forma parte del acervo de la Biblioteca Jurídica Virtual del Instituto de Investigaciones Jurídicas de la UNAM

talvez explique ou esteja entre os motivos da inexistência de julgado sobre o assunto até então.

Em diversas ocasiões, no entanto, o Tribunal já se manifestou sobre o direito de acesso à informação, educação e cultura, definindo os contornos e o alcance da proteção conferida pelos instrumentos normativos do SIDH. No julgamento do caso Claude Reyes y otros vs. Chile, em 19.09.2006, ${ }^{35}$ a Corte esclarece que a liberdade de pensamento e expressão abrange o direito de acesso à informação sob controle do Estado e que a previsão do artigo 13 da Convenção ampara tanto o direito das pessoas a acessar informações de interesse público quanto a obrigação positiva do Estado de fornecê-las, independentemente da apresentação de razões pelo solicitante. ${ }^{36}$

De fato, a informação é ferramenta indispensável de controle democrático das instituições, razão pela qual o direito à informação está ligado ao conceito de democracia participativa e respeito aos direitos fundamentais, de modo que a faculdade de comunicação e acesso à informação passam a ser formas irrenunciáveis de liberdade. ${ }^{37}$ Ocorre que, no mundo atual, as novas tecnologias da informação e comunicação figuram como instrumentos indispensáveis do acesso à informação em condições de igualdade pelos sujeitos sociais. Em outras palavras, a universalização do acesso às tecnologias informacionais é pré-condição da garantia dos direitos individuais de

ricana de Direitos Humanos. É o Protocolo de San Salvador que prevê a proteção e garantia desses direitos no âmbito do Sistema Interamericano de Proteção dos Direitos Humanos, porém, apenas os direitos sindicais e o direito à educação são justiçáveis, isto é, podem ser objeto do sistema de petições individuais. Os demais direitos estão sujeitos somente a um mecanismo de supervisão, de acordo com o disposto no artigo 19 do Protocolo.

35 O caso se referia à negativa do Estado do Chile de prestar informações sobre investimentos de uma empresa florestal no projeto de desflorestamento de montes nativos, que seria executado na $12^{a}$ região do Chile, para a instalação de uma serralheria e uma fábrica de chips, e que, segundo os denunciantes, poderia ser prejudicial ao meio ambiente e impedir o desenvolvimento sustentável da nação. A justificativa do Estado para a negativa das informações foi que estas estariam resguardadas pela confidencialidade relacionada ao direito de privacidade dos titulares da propriedade intelectual e tecnologia industrial. Na decisão, porém, a Corte afirma que a informação sonegada era de interesse público, em razão do impacto ambiental que o projeto poderia causar, e que ao negar o seu fornecimento o Estado violou o artigo 13 da Convenção Americana dos Direitos Humanos.

36 Corte Interamericana De Direitos Humanos (Corte IDH), Caso Claude Reyes y otros vs. Chile, sentencia de 19 de septiembre de 2006 (fondo, reparaciones y costas). Disponível em: http://www.corteidh.or.cr/docs/casos/articulos/seriec_151_esp.pdf. Acesso em 9 mai. 2015.

37 Pérez Luño, Antonio-Enrique, op. cit. 
Esta revista forma parte del acervo de la Biblioteca Jurídica Virtual del Instituto de Investigaciones Jurídicas de la UNAM

liberdade. Embora, como referido, a Corte Interamericana não tenha se manifestado, até o momento, sobre o tema específico das TICs, sua jurisprudência reconhece a indivisibilidade e interdependência dos direitos humanos, considerando-se que a efetiva garantia de uma série de direitos civis como direito à vida, à saúde, à integridade física e à liberdade só é possível se houver a garantia efetiva de direitos de segunda e terceira dimensões.

Por essa razão, a Corte costuma determinar medidas a serem adotadas pelos Estados em matéria econômica, social e cultural pela "via reflexa" ou por "ricochete". ${ }^{38}$ Assim, protege-se o núcleo essencial dos DESC através de sua vinculação com outros direitos, previstos na Convenção Americana. No entanto, apesar das saídas encontradas para proteger os direitos de segunda e terceira dimensões, continua sendo mais difícil fazer chegar ao Tribunal demandas diretas por DESC, em razão das restrições da Convenção e do próprio Protocolo de San Salvador.

Preenchendo a lacuna normativa do SIDH sobre regulação das novas tecnologias informacionais, em 13 de dezembro de 2013, a Comissão Interamericana de Direitos Humanos (CIDH) aprovou a Relatoria Especial para a Liberdade de Expressão "Libertad de Expresión e Internet". Atualmente este é o principal documento do sistema interamericano sobre os princípios orientadores da liberdade de expressão na internet, dentre os quais figuram o acesso em igualdade de condições, o pluralismo, a não discriminação e a privacidade. Todos os princípios reconhecidos pela $\mathrm{CIDH}$ possuem estreita inter-relação, de modo que o desrespeito a qualquer deles compromete a efetivação dos demais.

No que tange ao acesso à internet, as considerações da Comissão Interamericana de Direitos Humanos tem por base, além dos informes e declarações produzidos pela Organização das Nações Unidas (ONU) e da jurisprudência de outros sistemas — regionais e global— de proteção dos direitos humanos, as disposições do artigo $13^{39}$ da Convenção Americana

38 Mazzuoli, Valerio de Oliveira e Teixeira, Gustavo de Faria Moreira, "O direito internacional do meio ambiente e o greening da convenção americana sobre direitos humanos", Revista Direito GV, , São Paulo no. 9(1), jan-jun. 2013, pp. 199-242.

39 Artigo 13 - Liberdade de pensamento e de expressão: 1. Toda pessoa tem o direito à liberdade de pensamento e de expressão. Esse direito inclui a liberdade de procurar, receber e difundir informações e ideias de qualquer natureza, sem considerações de fronteiras, verbalmente ou por escrito, ou em forma impressa ou artística, ou por qualquer meio de sua escolha. 
Esta revista forma parte del acervo de la Biblioteca Jurídica Virtual del Instituto de Investigaciones Jurídicas de la UNAM

sobre Direitos Humanos e do artigo $2^{40}$ da Declaração de Princípios sobre Liberdade de Expressão, aprovada pela própria CIDH, em 2000.

A partir dessas disposições normativas, a Comissão Interamericana sustenta que a liberdade de expressão é um direito de dupla dimensão: possui uma dimensão individual e uma dimensão coletiva ou social. Tendo isso em conta, a liberdade de expressão é instrumento para o intercâmbio de informações e ideias entre as pessoas e para a comunicação massiva entre os seres humanos, o que implica tanto o direito de comunicar a outros o próprio ponto de vista e as informações ou opiniões que se queiram, como o direito de todos a receber e conhecer tais pontos de vista, informações, opiniões, relatos e notícias, livremente e sem interferências que as distorçam ou obscureçam. ${ }^{41}$

Com base em tais premissas e considerando o caráter tecnológico da sociedade contemporânea, a Relatoria Especial reconhece que o acesso à internet, devido a sua natureza multidirecional e interativa, sua velocidade e alcance global a um relativo baixo custo e seus princípios de descentralização e abertura, possui um potencial inédito para a realização efetiva do direito a buscar, receber e difundir informação em sua dupla dimensão, individual e coletiva. Além disso, destaca que a internet serve de plataforma para a realização de outros direitos humanos, como o direito a participar da vida cultural e gozar dos benefícios do progresso científico e tecnológico, o direito à educação, o direito de reunião e associação, os direitos políticos, o direito à saúde, dentre outros. ${ }^{42}$

Nesses termos, como modo de assegurar o gozo efetivo e universal do direito à liberdade de expressão, a Relatoria afirma que devem ser adotadas medidas para garantir, de maneira progressiva, o acesso de todas as pessoas à internet, o que requer ao menos três tipos de medidas: as medidas

40 2. Toda pessoa tem o direito de buscar, receber e divulgar informação e opiniões livremente, nos termos estipulados no Artigo 13 da Convenção Americana sobre Direitos Humanos. Todas as pessoas devem contar com igualdade de oportunidades para receber, buscar e divulgar informação por qualquer meio de comunicação, sem discriminação por nenhum motivo, inclusive os de raça, cor, religião, sexo, idioma, opiniões políticas ou de qualquer outra índole, origem nacional ou social, posição econômica, nascimento ou qualquer outra condição social.

${ }^{41}$ Comissão Interamericana De Direitos Humanos (CIDH), Libertad de Expresión e Internet: Relatoria Especial para a Liberdade de Expressão. Dez. 2013. Disponível em: http: / /www.oas.org/ es/cidh/expresion/temas/internet.asp. Acesso em 17 jun. 2015, p. 35.

42 Ibidem, par. 36. 
Esta revista forma parte del acervo de la Biblioteca Jurídica Virtual del Instituto de Investigaciones Jurídicas de la UNAM

positivas de inclusão, para resolver o problema do gap digital; os esforços de desenvolver planos para assegurar que a infraestrutura e os serviços garantam, progressivamente, o acesso universal; e medidas para proibir o bloqueio ou a limitação ao acesso à internet ou à parte desta. As duas primeiras medidas estão destinadas a erradicar a chamada "brecha digital", isto é, a separação entre quem tem acesso efetivo às tecnologias digitais e à informação, em particular à internet, e quem tem acesso muito limitado ou carece dele. ${ }^{43}$

Para tanto, a CIDH considera importante que as autoridades nacionais realizem esforços para erradicar progressivamente a brecha digital, amplamente reconhecida pelos Estados, seja em função da riqueza, gênero, demarcações geográficas ou grupos sociais. Além disso, a Comissão demonstra compreender que a brecha digital não está relacionada apenas com a disponibilidade do acesso à internet, mas também com a qualidade, ${ }^{44}$ a informação e os conhecimentos técnicos necessários para que o acesso à internet seja útil e proveitoso para os usuários. Nesse sentido, para alcançar efetivamente os objetivos mencionados, a Relatoria Especial insiste na importância de os Estados adotarem políticas e estratégias eficazes e concretas, elaboradas em consulta com pessoas e organizações de todos os setores da sociedade. ${ }^{45}$

Paralelamente ao problema da exclusão digital das classes desfavorecidas, existe ainda uma brecha de gênero entre mulheres e homens no acesso e uso das tecnologias da informação e comunicação. Este fator adicional de desigualdade é reconhecido pela Comissão Interamericana que, com vistas

43 Ibidem, par. 37-38.

44 Conforme afirmou o relator para liberdade de expressão Frank laRue durante o LacIGF VI, podemos comparar a política de acesso à internet como a política de água. Não basta que as pessoas tenham acesso à água. Ela precisa ser limpa, de boa qualidade, atender as necessidades humanas e para todos. Assim é o acesso à internet: deve ser universal e de qualidade. Artigo 19. Inclusão digital. Campanha banda larga é um direito seu. Artigo 19: Londres, s/d. Disponível em: http://artigo 19.org/liberdadedigital/category/inclusao-digital/. Acesso em: 02 jun. 2015.

45 Neste ponto, a Comissão Interamericana de Direitos Humanos reconhece que o compromisso de erradicar a brecha digital tem inspirado a adoção de medidas encaminhadas a aumentar a disponibilidade de tecnologias da informação e comunicação, como programas de distribuição de computadores portáteis esequíveis. Ademais, alguns Estados têm estabelecido pontos de acesso público, os quais resultam importantes para facilitar o acesso dos grupos mais vulneráveis, que carecem de computadores pessoais. Ibidem, par. 40. 
Esta revista forma parte del acervo de la Biblioteca Jurídica Virtual del Instituto de Investigaciones Jurídicas de la UNAM

à sua eliminação, determina que os Estados devem tomar medidas para promover a participação das mulheres na sociedade da informação, a fim de contribuir ao seu empoderamento e à igualdade de gênero. A Relatoria Especial não deixa de asseverar, ainda, que o acesso universal à internet conduz à obrigação de elaborar políticas que outorguem oportunidades de acesso equitativo e uso eficiente para todos os setores, em especial para as pessoas com deficiência. ${ }^{46}$

Indo mais além, o texto da Relatoria Especial afirma que a garantia da participação de minorias linguísticas, assim como a disponibilidade de conteúdo local na internet, são requisitos para que o acesso à internet constitua autenticamente um instrumento que fomente o pluralismo informativo e a diversidade cultural. Fazendo referência a decisões da Corte Interamericana, a Comissão declara que o direito à liberdade de expressão implica necessariamente o direito das pessoas a utilizar o idioma que elejam para se expressar. Em atenção a isso, faz-se necessário que os Estados adotem medidas tendentes a reduzir os obstáculos linguísticos para garantir que as distintas culturas possam se expressar e acessar a internet. ${ }^{47}$

Um segundo tipo de medidas que, de acordo com a Comissão Interamericana, deriva do direito universal de acesso se refere à necessidade de adotar planos de ação detalhados de vários anos de duração a fim de que a internet resulte amplamente disponível e acessível. Para esse fim, os Estados devem adotar e promover as políticas públicas necessárias para gerar a infraestrutura de acesso universal que permita a construção de uma sociedade de conhecimento, evitando situações arbitrárias de exclusão social. Isto inclui a elaboração de planos nacionais de banda larga e a promoção da incorporação de infraestrutura física, assim como a adoção de medidas para o desenvolvimento da internet móvel. ${ }^{48}$

$\mathrm{Na}$ mesma trilha, é preciso adotar regulações e políticas públicas que promovam a interoperabilidade e interconexão de internet a nível global, de modo a fomentar o livre fluxo de ideias e evitar o surgimento de barreiras tecnológicas territoriais que ocasionem a fragmentação da internet a nível nacional ou regional, e a consequente limitação da liberdade de expressão e acesso à informação. Além disso, tais regulamentações devem

\footnotetext{
46 Ibidem, par. 41-42.

47 Ibidem, par. 44.

48 Ibidem, par. 45
} 
Esta revista forma parte del acervo de la Biblioteca Jurídica Virtual del Instituto de Investigaciones Jurídicas de la UNAM

contemplar, por exemplo, um regime de preços que fomente o acesso amplo à internet, incluindo os setores vulneráveis e as zonas rurais mais distantes. Para tanto, os Estados devem facilitar o acesso através de programas de distribuição de computadores e da criação de centros comunitários de tecnologias da informação e outros pontos de acesso público. ${ }^{49}$

Por fim, a Comissão Interamericana registra que o direito de acesso não supõe apenas a adoção de medidas positivas, mas inclui também o direito de todas as pessoas de que não se bloqueie ou interrompa arbitrariamente sua possibilidade de acesso à internet ou qualquer parte desta. Com isso, afirma estar proibida a interrupção do acesso à internet, seja a populações inteiras ou a determinados segmentos; a negação de acesso à internet como meio de sanção; e as medidas de redução de velocidade de navegação de internet com fins distintos à gestão razoável do tráfego, já que todos esses intentos violam radicalmente o direito de liberdade de expressão na internet. ${ }^{50}$

Também, em atenção a obrigação de garantir o direito à liberdade de expressão, a Comissão determina que os Estados devem adotar medidas para prevenir ou remediar restrições ilegítimas ao acesso à internet por parte de particulares e empresas, como as políticas que atentam contra a neutralidade da rede ou a prevalência de práticas anticompetitivas. ${ }^{51}$

A análise do conteúdo, aqui exposto, da Relatoria Especial para a Liberdade de Expressão "Libertad de Expresión e Internet”, permite concluir, preliminarmente, que o Sistema Interamericano de proteção dos Direitos Humanos, em consonância com a orientação de outros sistemas e organismos internacionais, especialmente a ONU, e também com os estudos sociológicos referidos no item 1.1 deste trabalho, reconhece a centralidade da garantia do acesso à informação no mundo atual, assim como a imprescindibilidade da disposição universal dos meios tecnológicos necessários ao acesso. Sob tais fundamentos, o Organismo elenca um rol de deveres a serem cumpridos pelos Estados-membros para que a toda a região caminhe no sentido da universalização do acesso à internet de qualidade.

49 Ibidem, par. 46/47.

50 Neste sentido, por exemplo, a Relatoria Especial expressa sua preocupação a respeito de informações sobre a suspensão dos serviços de telefonia móvel e internet em zonas onde se realizavam protestos contra megaprojetos de infraestrutura, afetando-se assim as possibilidades de comunicação de manifestantes e jornalistas sobre acontecimentos de interesse público. Ibidem, par. 50 .

51 Ibidem, par. 51. 
Tanto a doutrina sociológica quanto a orientação do Sistema Interamericano de Direitos Humanos, ambas aqui expostas tratam do reconhecimento do imperativo de universalização do acesso à internet com vistas ao plenipotencial desenvolvimento da liberdade humana na rede. No entanto, diante da complexidade da sociedade da informação contemporânea, a problemática do acesso e da liberdade encontra-se indissociável de uma reflexão sob a ótica do mito de Janus, o Deus com duas faces, a dualidade entre o bem e o mau, entre o positivo e o negativo. Com efeito, ao passo que a liberdade passa a ser um valor ampliado com o uso das novas tecnologias da informação e da comunicação, o rescrudescimento do controle e da vigilância das informações que circulam na rede é a outra face da moeda.

\section{DO BIG BROTHER AO CÍRCULO: A ERA DO ACESSO E OS RISCOS DE CONTROLE TOTAL}

A alteração de paradigmas sociais e a consequente passagem da sociedade industrial do século XX para a sociedade da informação do século XXI traz mudanças substanciais para as relações sociais. A mudança do paradigma da posse/propriedade ${ }^{52}$ e do poder como exploração ${ }^{53}$ para os paradigmas do acesso $^{54}$ e do poder como exclusão ${ }^{55}$ demonstra que, quando o acesso passa a ser a pedra de toque da sociedade, a liberdade passa a ser algo diferente.

Enquanto sob a égide da sociedade industrial, as relações de propriedade eram o paradigma de domínio que emergia na organização da atividade humana, a liberdade aparecia como conceito vinculado à ideia de autonomia e de posse. Segundo Rifkin, ${ }^{56}$ ser livre era ser autônomo, possuir determinada propriedade e não ser subordinado a outros. Basta relembrar, ainda que de modo superficial, das lições de Marx segundo as quais no sistema capitalista quem detém o poder são os donos dos meios de produção que exploram a mão de obra dos operários fabris.

52 Rifkin, Jeremy, A Era do Acesso, traduzido por Maria Lucia G. L. Rosa, São Paulo, Makron Books, 2001, p. 194.

53 Lash, Scott, Crítica de la información, tradução Horácio Pons, Buenos Aires, Amorrotu, 2005, p. 11.

54 Rifkin, Jeremy, op. cit.

55 Lash, Scott, op. cit.

56 Rifkin, Jeremy, op. cit. p. 196. 
Esta revista forma parte del acervo de la Biblioteca Jurídica Virtual del Instituto de Investigaciones Jurídicas de la UNAM

Todavia, em tempos de sociedade informacional, em uma economia de redes de fornecedores e usuários, a liberdade passa a ser vinculada ao fato de se estar conectado. Como bem explica Rifkin, ${ }^{57}$ a inclusão e o acesso tornam-se as provas mais importantes da liberdade pessoal de um indivíduo. A autonomia passa a não ser mais um corolário da liberdade, vez que, ser autônomo na sociedade informacional é ser isolado, desconectado e, a base para se aquilatar a liberdade pessoal é o direito de não ser excluído dos fluxos em rede, o direito de acesso.

De forma paradoxal, contudo, embora o direito de acesso e sua universalização seja hoje basilar para o desenvolvimento de liberdades, é nessa mesma esfera que encontramos os riscos oriundos de uma cultura de controle da rede. Como destaca Castells ${ }^{58}$ a internet fora criada como um meio para a liberdade. Um exemplo disso é seu local de nascimento e desenvolvimento, os Estados Unidos, país em que a liberdade de expressão ocupa lugar de destaque não só em normas, como é o caso da Primeira Emenda à Constituição, mas em decisões de tribunais americanos.

No entanto, os dois fundamentos básicos da internet — liberdade e privacidade - encontram-se desafiados por novas tecnologias e regulações. O desenvolvimento de novas arquiteturas de software permite o controle das comunicações e, governos toleram tais tecnologias de vigilância ou as adotam para recuperar parte do poder que fora perdido com a eclosão da internet como um fenômeno mundial e transfronteiriço. ${ }^{59}$

Sob a égide deste paradigma, faz-se-, no presente capítulo, uma análise primeiramente sociológica sobre a universalização do controle na sociedade da informação (2.1), demonstrando ser um problema global o do risco de vigilância absoluta pelos Estados e atores privados do conteúdo de comunicações e dados pessoais dos usuários de internet e de novas tecnologias de comunicação e informação. Na sequência, é feita uma análise da interpretação do Sistema Interamericano de Direitos Humanos acerca do risco da consolidação de uma sociedade desregrada da vigilância (2.2).

57 Ibidem, p. 197.

58 Castells, Manuel, A galáxia da Internet: reflexões sobre a Internet, negócios e a sociedade, traduzido por Maria Luiza X. de A. Borges, Rio de Janeiro, Jorge Zahar Ed., 2003, p. 139.

59 Ibidem, p. 140. 


\section{A universalização do controle na sociedade da informação}

As novas tecnologias de liberdade, consoante já fora aludido na introdução deste capítulo, estão sendo opostas a tecnologias de controle, sendo que o crescimento do uso destas últimas resulta da mercantilização, ou seja, da necessidade de assegurar e identificar a comunicação virtual para atendimento de finalidades econômicas. Nesse sentido, em tempos de aceleração social e de primazia da velocidade e da brevidade nas comunicações, o desenvolvimento da racionalidade econômica confunde-se com o desenvolvimento da racionalidade tecnocientífica. ${ }^{60}$

A ideia de recusa à qualquer limitação ao progresso tecnocientífico faz emergir os riscos de um controle total e do cerceamento da privacidade em prol de uma noção de segurança. Nesse mesmo sentido, pode-se relembrar das lições de Giddens, ${ }^{61}$ para quem a alta modernidade é a era em que o desenvolvimento científico trabalha em prol das regras de mercado em que os sistemas técnicos e peritos possuem elevado grau de importância. Inclusive, o déficit informacional, bem como a vulnerabilidade técnica são corolários para os riscos de controle total advindos da era do acesso.

Milton Santos, ${ }^{62}$ nesse mesmo viés, assevera que a técnica é a grande banalidade e o grande enigma desde meados do século XX, e é como enigma que ela comanda a vida dos indivíduos,impondo relações, modelando nosso entorno e administrando nossas relações com o meio que nos cerca. Segundo o autor, ontem a técnica era submetida, hoje, sendo conduzida pelos grandes atores da economia e da política, ela é quem submete. Assim, mesmo com toda a liberdade potencialmente trazida pelo acesso, o homem se torna escravizado.

Sob esse panorama, para as observações de liberdade e controle na sociedade informacional, é importante analisar que quanto maior o poder dos seres de usar as leis da natureza a seu favor, maior o grau de liberdade do uso dessas leis e menor a sujeição a elas. O uso de máquinas marca a emancipação da vigência das leis naturais e a aparição da liberdade para o uso dessas leis caracteriza o tempo em que os seres assumem cada vez mais

60 Santos, Laymert Garcia, Politizar as novas tecnologias. O impacto sociotécnico da informação digital e genética, São Paulo, Ed. 34, 2003, p. 230.

61 Giddens, Anthony, As consequências da modernidade, traduzido por Raul Fiker, São Paulo, Editora UNESP, 1991.

62 Santos, Milton, op. cit. 
Esta revista forma parte del acervo de la Biblioteca Jurídica Virtual del Instituto de Investigaciones Jurídicas de la UNAM www.juridicas.unam.mx

o controle das leis naturais. Não obstante tal premissa, a era da aceleração social ${ }^{63}$ promove de modo paradoxal o movimento inverso, em que o controlador é cada vez mais controlado pelo objeto por ele próprio criado, em uma espécie de dependência.

Já na distopia literária de Arthur C. Clark, 2001: Uma Odisseia no Espaço, escrita em 1968, uma crítica a esse panorama vivido hoje é feita, justamente no momento em que o computador HAL demonstra mais emoções que os próprios tripulantes da viagem espacial. Desvela-se, portanto, desde meados do século XX a crítica a essa inversão de paradigma que hoje se vislumbra de modo claro: o aprisionamento do homem às condições impostas pela máquina, a perda de humanidade decorrente dessa situação e o processo de mecanização do ser humano.

Com a suplantação das tecnologias mecânicas pelas tecnologias de informação, a era do acesso surge marcada não só pela dependência do homem em relação a suas criações tecnológicas, como pelo controle exercido por softwares específicos e pela influência da sociedade da vigilância. Como assevera Paul Virilio ${ }^{64}$ lares se tornam objetos de vigilância ou de televigilância, vez que o objetivo hoje não é mais informar ou divertir a massa de telespectadores, mas expor e invadir o espaço doméstico com compartilhamento de angústias, medos e superexposição em tempo real.

Passa-se da era do Big Brother, ${ }^{65}$ em que a vigilância era feita de modo concentrado, como na estrutura de um panóptico, para a era do Círculo. ${ }^{66}$

63 Rosa, Artmut, Aliénation et accélération, Paris, Découvert, 2012.

64 Virilio, Paul. La bombe informatique. Paris, Galilée, 1998, p. 70.

65 Faz-se aqui referência ao livro 1984 de George Orwell, romance distópico, publicado em 1949, que retrata o cotidiano de uma sociedade em que se desenvolve um regime totalitário, e repressivo. Uma das formas de controle sobre os indivíduos constitui-se pelo uso de tele telas nas próprias residências, as quais permitiam que as autoridades competentes vigiassem os indivíduos. O Big Brother, ou Grande Irmão é, no romance, um personagem fictício, é o líder máximo dessa sociedade autoritária, o responsável por incutir o medo nos cidadãos e aquele que está constantemente vigiando a todos.

66 A referência é feita ao romance de Dave Eggers, lançado em 2014, que traduz a realidade da comunicação e da transferência constante e ininterrupta da vida real para a virtual, por meio de redes sociais. Em tal romance, a empresa O Círculo ocupa um dos papeis de destaque, uma vez que convence as pessoas a criar uma identidade verdadeira na internet. Todavia, os requisitos para tal identidade são a transparência e a constante conectividade. Tudo que acontece na vida real deve ser transposto para a tela de um computador ou postado em rede social, visto que isso facilita a vigilância e o controle de todos sobre todos. 
Sob esse panorama, Castells ${ }^{67}$ afirma que não é mais o Big Brother como único centro o responsável pelo controle, mas uma multidão de softwares, agências de vigilância e processamento de informações que registram o comportamento dos usuários da rede em todos os momentos de acesso, enquanto bancos de dados os mantém guardados. E essa multiplicidade de fontes de controle deriva do fato de que, diferentemente da sociedade industrial e mecanizada que tinha em Estados autoritários formas de controle, na sociedade da informação, o ingrediente essencial na construção do sistema de vigilância e controle deriva das empresas, em consonância com os Estados.

Milton Santos ${ }^{68}$ afirma que somente os atores hegemônicos se servem de todas as redes e utilizam todos os territórios e, segundo Delmas-Marty, ${ }^{69}$ na sociedade mundializada, dois são os atores hegemônicos principais: os Estados — titulares de poder político — e as empresas, sobretudo as transnacionais — titulares de poder econômico-. Assim, as novas tecnologias informacionais e os sistemas de engenharia criados em cada país podem ser melhor utilizados por empresas transnacionais do que pela própria sociedade nacional.

Através de softwares desenvolvidos principalmente por esses atores econômicos da mundialização, televigilância não se resume ao controle por meio de imagens digitalizadas das pessoas em seus respectivos ambientes domésticos, mas passa a ser o entrecruzamento e o processamento de dados que cada indivíduo deixa na rede mundial de computadores ao transitar nos diversos sistemas informatizados. Pode-se dizer que o indivíduo aqui se desumaniza não propriamente no sentido da mecanização do homem, mas de sua transformação em mero fluxo de dados.

Passamos à era do acesso e da transparência que apresenta, como um de seus componentes, aquilo que Paul Virilio ${ }^{70}$ denomina como "transparência das aparências instantaneamente transmitidas à distância”. Qual seja, o controle da vida de um indivíduo ou de um grupo de indivíduos somente por meio do rastreamento de seu tráfego online ou de suas publicações na rede. Nesse sentido, como afirma Laymert Garcia dos Santos, ${ }^{71}$ a inocência

67 Castells, Manuel, op. cit., p. 146.

68 Santos, Milton, op. cit.

69 Delmas-Marty, Mireille, Résister, responsabiliser, anteciper, Paris, Seuil, 2013.

70 Virilio, Paul, op. cit..

71 Santos, Laymert Garcia, op. cit., p. 140. 
Esta revista forma parte del acervo de la Biblioteca Jurídica Virtual del Instituto de Investigaciones Jurídicas de la UNAM

do usuário que frequentemente não possui conhecimento dos softwares ou outros sistemas que vigiam seus padrões de comportamento virtual para coleta de dados pessoais encontra paralelo na estreita relação entre controle do acesso à esfera digital e controle do acesso às informações do usuário, vez que a informação no século XXI passa a ser uma arma fundamental não só à economia como à geopolítica.

Assim, como moeda de troca valiosa, é preciso lembrar que ao passo que existe o fluxo de informações no sentido provedor-usuário denotando a liberdade deste para navegar e usufruir da rede, o sentido inverso também existe, sendo esta a característica do controle. Por isso, é inevitável que na sociedade informacional, em se tratando de fluxos de informações, liberdade e controle são duas faces de uma mesma moeda.

No entanto, como bem refere Laymert dos Santos, ${ }^{72}$ se acessar e processar as informações dos usuários é quase uma decorrência natural das atividades dos provedores, a recíproca não procede, uma vez que é muito difícil que o cidadão comum que navega na rede tenha meios de acessar informações de empresas que não estão disponíveis ou que não são divulgadas na internet.

A vulnerabilidade e a necessidade de inclusão digital afastam a ideia de segurança e proteção de dados individuais e abrem espaço para os riscos de controle total. Estamos sob a égide de uma nova lógica de dominação, como assevera Deleuze, ${ }^{73}$ na qual se passa de uma sociedade disciplinar para a sociedade do controle. O panóptico de prisões, manicômios e escolas como centros de vigilância de muitos por poucos e de propagação de um poder disciplinar cede espaço às múltiplas e multifocais formas de controle, sobretudo por meio da internet. Há, portanto, substituição dos grandes meios de confinamento por novas formas de controle aberto:

Nas sociedades de controle, ao contrário, o essencial não é mais uma assinatura nem um número, mas uma cifra: a cifra é uma senha ao passo que as sociedades disciplinares são reguladas por palavras de ordem (tanto sob o ponto de vista da integração quanto da resistência). A linguagem numérica do controle é feita de cifras que marcam o acesso à informação ou à rejeição. Não se está mais diante do

72 Ibidem, p. 145.

73 Deleuze, Gilles, Conversações, tradução de Peter Pál Pelbert, São Paulo, Editora 34, 1992, p. 222. 
Esta revista forma parte del acervo de la Biblioteca Jurídica Virtual del Instituto de Investigaciones Jurídicas de la UNAM

par massa-indivíduo. Os indivíduos tornaram-se "dividuais”, divisíveis, e as massas tornaram-se amostras, dados, bancos ou mercados. ${ }^{74}$

É possível então afirmar que o modelo do panóptico não é mais suficiente para descrever os impasses da sociedade informacional. Não há motivos para crer que a consciência da vigilância limite a imaginação ou reprima a criatividade dos Estados ou das empresas. As forças de atuação de tais instituições hoje não se opõem a de um panóptico, uma vez que as novas formas de vigilância implicam a observância dos indivíduos potencialmente por todos e sempre por muitos.

Segundo Vaidhyanathan ${ }^{75}$ o que temos hoje é um “Críptico", uma vez que ao contrário da sujeição às estruturas de panóptico, os indivíduos não sabem como estão sendo observados ou de que modo seus perfis estão sendo traçados, sendo que os comportamentos não se alteram em função dessa existente, porém não tão conhecida vigilância.

A tirania do dinheiro e a importância do domínio da informação fazem com que a manipulação e a apropriação de dados seja uma das tarefas mais caras a Estados e empresas no século XXI. Essa era de controle permanente, advindo tanto de esferas públicas como privadas demonstram que a internet privilegia a desterritorialização e o imediatismo e, com isso, um problema político e geopolítico vem à tona: a ausência de marcos internacionais eficazes para realizar frente aos sistemas de vigilância.

A própria morfologia da rede é uma fonte de reorganização das relações de poder. As conexões que ligam as redes, como é o caso de fluxos financeiros que assumem o controle de impérios midiáticos, que por sua vez, influenciam processos políticos, representam os instrumentos privilegiados do poder. Os conectores passam a ser detentores de poder, ${ }^{76}$ uma vez que, a economia da sociedade da informação organiza-se em torno de redes globais de capital, gerenciamento e informação e, o acesso a know-how tecnológico é de suma importância para a produtividade e para a competividade. ${ }^{77}$

74 Idem.

75 Vaidhyanathan, Siva, A googlelização de tudo: e por que devemos nos preocupar. A ameaça do controle total da informação por meio da maior e mais bem sucedida empresa do mundo virtual, São Paulo, Editora Cultrix, 2011, p. 128.

76 Castells, Manuel, A Era da Informação: economia, sociedade e cultura, vol. 1 (Sociedade em Rede), São Paulo, Paz e Terra, 1999, p. 566.

77 Idem. 
Esta revista forma parte del acervo de la Biblioteca Jurídica Virtual del Instituto de Investigaciones Jurídicas de la UNAM

Indubitável que as novas tecnologias de informação e comunicação, com destaque para a internet, possuem a capacidade de ampliar o espectro de comunicações humanas sob a ótica da liberdade de expressão e de comunicação, por exemplo. No entanto, a lógica da aceleração social, ${ }^{78} \mathrm{em}$ sua perspectiva técnica, provoca efeitos significativos sobre a realidade social, pois assim como se recebem rapidamente informações, em nome da aceleração, direitos individuais e coletivos são violados, não só pelos Estados, como por empresas nacionais ou transnacionais. Há maior comunicação, porém maior vigilância.

Prova disso são alguns casos emblemáticos que ocuparam lugares de destaque em grandes tabloides internacionais. Um desses casos é o Wikileaks, site coordenado por Julian Assange que se caracterizava pela publicação de documentos sigilosos, principalmente do governo dos Estados Unidos. Tal plataforma virtual tinha por objetivo realizar denúncias de corrupção e eventuais violações de direitos humanos por meio da divulgação de informações confidenciais tendo a transparência como base e utilizando-se da apropriação das informações sigilosas por meio de invasões hackers nos computadores do governo e de empresas associadas.

Outro caso emblemático evolvendo denúncias de espionagem na internet foi o caso Edward Snowden. Por meio de Snowden, ex-funcionário da Agência de Segurança Nacional (NSA) norte americana, houve o vazamento de informações referente à empresa de comunicação Verizon, que teria sido obrigada a fornecer ao governo milhões de registros telefônicos feitos por cidadãos civis norte americanos. Além disso, relatou-se a existência do programa da Agência Nacional de Segurança dos Estados Unidos chamado de PRISM, programa que tinha como objetivo revelar informações de pessoas em todo o mundo que utilizavam os serviços de grandes empresas como Google e Facebook.

Com o desvelamento de operações de espionagem do governo norte americano sobre os dados pessoais de seus cidadãos e em relação a outros países tanto europeus, quanto latino americanos, como é o caso do Brasil, tensões diplomáticas foram estabelecidas. Inclusive, a aprovação em território brasileiro da lei que constitui o Marco Civil da Internet foi agilizada em função da descoberta dos procedimentos de espionagem.

78 Rosa, Artmut, op. cit. 
Além disso, no mesmo sentido do Patriot Act, ${ }^{79}$ a França após os atentados de janeiros de 2015 contra a redação do jornal Charlie Hebdo, aprovou, em 19 de março de 2015, pelo Conselho de Ministros, a Loi de renseignement (Lei de informação). Tal aprovação ganhou notoriedade em abril, mês em que um grupo chamado Cybercaliphate, vinculado ao grupo Estado Islâmico, atacou e tirou do ar por algumas horas tanto os canais de televisão vinculados à TV5Monde, como sites e perfis em redes sociais da mesma rede.

Em função disso, a declaração do Ministro da Cultura da França é a de que a prioridade em se tratando de comunicação e difusão de informações será a ciberdefesa e a cibersegurança. Todavia, existe a preocupação de que tal lei seja o Patriot Act francês, com o risco de controle dos dados e dos fluxos de comunicação dos cidadãos na rede e com graves erosões de liberdades públicas.

Independentemente da regulação normativa, sabe-se que a tecnologia viabiliza a vigilância total de todas as comunicações. Segundo relata Jérémie Zimmermann, em sua interlocução com Julian Assange, Jacob Appelbaum e Andy Müller-Maguhn, na obra Cypherpunks, os Estados democráticos da Europa estão construindo um número enorme de máquinas que lhes permitem agir exatamente fora da lei no que se refere à interceptação, porque "eles não precisam de uma decisão judicial, eles podem simplesmente ligar as máquinas e interceptar os dados, e essa tecnologia não pode ser controlada". ${ }^{80}$

Para Zimmermann, a interceptação estratégica — que implica interceptar todo mundo, independente de serem inocentes ou culpados - não pode ser restringida pela legislação, pois "a tecnologia é inerentemente tão complexa, e a sua utilização, na prática, tão secreta, que não pode haver uma supervisão democrática expressiva” ${ }^{81}$ Em concordância, Assange argumenta que "é simplesmente impossível controlar a interceptação em massa por meio da legislação e da política. Simplesmente não vai acontecer”, afinal, "como seria possível garantir o cumprimento dessas restrições

79 Houve logo após os atentados terroristas de 11 de setembro em Nova York a edição do Patriot Act, uma lei que supervaloriza os serviços de informação em detrimento das liberdades dos cidadãos. Na prática, tal lei autoriza os serviços de segurança a terem acesso a dados informáticos detidos por particulares e por empresas sem autorização prévia.

80 Assange, Julian, op. cit. p. 52.

81 Ibidem, p. 53. 
uma vez montado um sistema de interceptação que, ainda por cima, é operado por um órgão secreto de espionagem? É impossível”. ${ }^{82}$

Paralelamente a isso, as reações estatais não somente a ataques cibernéticos ou denúncias de espionagem digital através da edição de leis que supervalorizam os serviços de informação e o controle massivo dos usuários da rede acabam se aproximando daquilo que Giorgio Agambem ${ }^{83}$ descreve como Estado de Exceção. Nesse sentido, sob o argumento de segurança nacional, surgem instrumentos normativos potencialmente justificadores de uma vigilância sobre os indivíduos e que nem sempre possuem como valor preponderante a garantia de liberdade no uso da rede.

Através desse panorama descrito, embora a internet seja mundial e com pretensão universal, em uma eventual tentativa de regulação para o equilíbrio ou ao menos a tentativa de equilíbrio entre liberdade e controle, percebe-se a intervenção de instâncias internacionais, regionais, nacionais e locais. Dessa feita, a partir da descrição do cenário de controle e vigilância no seio da sociedade informacional, cabe agora trabalhar com o modo como a jurisdição responde a tais questões, com enfoque no posicionamento do Sistema Interamericano de proteção dos Direitos Humanos.

\section{Visões do sistema interamericano de proteção dos direitos humanos sob a perspectiva do controle na sociedade informacional}

Consoante se tentou demonstrar no subcapítulo anterior, a sociedade da informação e suas novas tecnologias, como é o caso da internet, não só possibilitam rapidez na difusão de informações e troca de comunicações, como, em proporções semelhantes, possibilitam o aumento do controle, tanto por parte de empresas privadas quanto de Estados em conteúdos de comunicações e metadados dos indivíduos.

A internet, portanto, em seu avanço nas últimas décadas, criou oportunidades sem precedentes para a livre expressão, comunicação, busca, posse e intercâmbio de informações, facilitando-se o desenvolvimento e a circulação de grandes quantidades de dados sobre as pessoas. Porém, essa

82 Idem.

83 Agaben, Giorgio, Estado de Exceção, trad. Iraci D. Poleti, 2. ed. São Paulo, Boitempo, 2004 (Estado de Sítio). 
informação, manejada em arquivos, facilmente acessível e sistematizável, pode ser altamente reveladora de dados sensíveis e pessoais e, em função disso, os riscos advindos de sistemas de controle e de vigilância em diferentes níveis (internacional, regional, nacional e local) devem ocupar uma das pautas atuais em relação ao tema de regulação da rede. ${ }^{84}$

Embora esse fenômeno de vigilância seja global, almeja-se aqui realizar uma análise do posicionamento do Sistema Interamericano de Direitos Humanos (SIDH) acerca dos riscos de controle e de vigilância em relação a possíveis violações de Direitos Humanos. Pode-se afirmar que até os dias atuais, não existem casos julgados pela Corte Interamericana de Direitos Humanos envolvendo violações de direitos de privacidade e de liberdade de expressão dos indivíduos na internet por meio de vigilância ilegal ou espionagem clandestina. Isso, em grande medida, se justifica pelo fato de que descobertas em relação ao controle e invasão estatal ou privada em comunicações e registro de dados de usuários da rede ainda é algo extremamente recente, com o acréscimo de uma questão de vulnerabilidade técnica da maioria dos cidadãos, que não possuem recursos suficientes para que possam saber em que pontos ou em que medida estão sendo vigiados.

Soma-se a isso, o fato de que até hoje, grande parte do histórico de julgamento da Corte Interamericana envolveu casos relativos a violações de direitos humanos perpetradas pelo Estado durante o período de ascensão de autoritarismos e ditaduras na América Latina. Hoje o espectro de casos apresentados para julgamento pelo órgão jurisdicional diferencia-se um pouco e relaciona-se aos direitos econômicos, culturais e sociais dos países do Sul da América.

Todavia, embora não existam precedentes jurisprudenciais, é preciso que se destaque nesse tópico o posicionamento do Sistema Interamericano de Proteção dos Direitos Humanos em relação aos processos de vigilância da rede tanto por parte de entes públicos quanto por parte de atores privados. O principal documento a respeito do tema, já citado e parcialmente analisado no capítulo 1, é a Relatoria Especial para a Liberdade de Expressão "Libertad de Expresión e Internet", da Comissão Interamericana de Direitos Humanos.

84 Organização Das Nações Unidas (ONU)-Organização Dos Estados Americanos, Declaração conjunta sobre programas de vigilância e seus impactos sobre a liberdade de expressão, 2013. Disponível em: http://www.oas.org/pt/cidh/expressao/showarticle.asp?artID=926\&lID =4. Acesso 03 jun 2015. 
Esta revista forma parte del acervo de la Biblioteca Jurídica Virtual del Instituto de Investigaciones Jurídicas de la UNAM

A partir desse documento, vislumbra-se que o tema do controle e da vigilância sobre conteúdos e dados de usuários da internet por parte dos Estados e de atores privados é motivo de atenção do sistema regional de proteção dos direitos humanos na América. Isto porque a vigilância, consoante fora demonstrado, é uma realidade que gera riscos de violações de dois direitos humanos fundamentais: o direito à privacidade e o direito à liberdade de pensamento e expressão, riscos que poderiam ser minimizados através de revisão legislativa e de estabelecimentos de mecanismos de transparência em relação aos atos de controle e vigilância.

Com base na Relatoria, verifica-se que o posicionamento latino-americano sobre a temática se encontra afinado com declarações e relatórios da Organização das Nações Unidas (ONU), bem como com precedentes jurisprudenciais do Tribunal Europeu dos Direitos do Homem (Tribunal de Estrasburgo). Nesse sentido, é merecido o destaque para a Declaração conjunta da ONU e da OEA sobre Programas de Vigilância e seus Impactos sobre a Liberdade de Expressão, elaborada pouco tempo depois dos escândalos envolvendo a divulgação de informações sobre espionagem clandestina por parte do governo norte-americano no caso Edward Snowden.

Tal declaração expõe a preocupação em relação à existência de programas e práticas de segurança que possam gerar prejuízos sérios aos direitos de intimidade e de liberdade de expressão e pensamento ${ }^{85}$ Para tanto, apresenta alguns princípios basilares do direito internacional que servem para orientar o desenho e implementação de programas de vigilância virtual e tecnológica destinados à luta contra o terrorismo e a prevenção de crimes cibernéticos, porém, tendo como norte o respeito aos direitos humanos.

Assim, uma das primeiras premissas é a de garantir a proteção à segurança nacional com observância de standards internacionais em matéria de direitos humanos. Nesse sentido, é interessante destacar que duas são as situações principais em que é considerado legítimo o uso excepcional, previsto por lei, de programas de vigilância de conteúdos e dados na rede: a prevenção de crimes e a segurança nacional, com vistas à prevenção e ao combate ao terrorismo. ${ }^{86}$ Mesmo assim, a utilização dos programas de vigi-

85 Organização Das Nações Unidas (ONU). Organização Dos Estados Americanos. Declaração conjunta sobre programas de vigilância e seus impactos sobre a liberdade de expressão. 2013. Disponível em: http://www.oas.org/pt/cidh/expressao/showarticle.asp? artID=926\&lID =4. Acesso 03 jun 2015.

86 Comissão Interamericana De Direitos Humanos (CIDH), Libertad de Expresión e Internet..., cit. 
lância deverá respeitar os princípios da necessidade e da proporcionalidade, bem como visar o respeito às normas internacionais de direitos humanos relativas à intimidade, à privacidade e à liberdade de expressão.

Outra premissa da Declaração é a necessidade de limitar os programas de vigilância. Isso porque a Declaração Universal dos Direitos do Homem, o Pacto Internacional pelos Direitos Civis e Políticos, a Convenção Americana de Direitos Humanos e a Declaração Americana de Direitos e Deveres do Homem próbem interferências arbitrárias ou abusivas na vida privada dos indivíduos, incluindo-se nesse âmbito, as comunicações. Para tanto, as leis para regulação dos sistemas de vigilância devem estabelecer limites em relação à natureza, ao alcance e à duração desse tipo de ato por parte dos Estados ou de atores privados e, o acesso a dados pessoais somente poderá acontecer em circunstâncias excepcionais definidas em legislação.

Em tal documento internacional e de cariz também regional, dois últimos princípios expostos são os de dever de publicidade e transparência e de sanções por divulgação de informações reservadas. Sobre a questão da transparência, para que não haja riscos ou eventuais arbitrariedades, as leis reguladoras dos sistemas de vigilância devem assegurar o acesso à informação sobre os programas de vigilância de comunicações privadas, seu alcance e seus controles. Além disso, a declaração afirma que os Estados devem criar mecanismos de controle independente, capazes de assegurar transparência e prestação de contas.

Por tal documento, portanto, reconhecem-se os riscos de uma vigilância excessiva caso regras para a proteção de direitos de intimidade, privacidade e liberdade de expressão não forem criadas e adequadamente regulamentadas. Ainda, destaca-se a necessidade de gerar as condições para que a implementação de programas de controle seja legítima e ajustada às regras de proteção internacional dos direitos humanos. Evidente que sem tais condições, a interceptação e retenção de dados de comunicações privadas ocasionam riscos aos indivíduos.

Nesse viés, o Relatório do Relator Especial sobre Promoção e Proteção do Direito à Liberdade de Expressão, Frank la Rue, da ONU (A/ HRC/23/40) traz a questão da importância de entender as modalidades de vigilância de dados e comunicações atualmente, bem como a imperiosa necessidade de, para a redução de riscos, haver uma revisão de leis nacionais sobre a temática, as quais em sua maioria encontram-se obsoletas e em 
Esta revista forma parte del acervo de la Biblioteca Jurídica Virtual del Instituto de Investigaciones Jurídicas de la UNAM

desconformidade com marcos normativos internacionais de proteção aos direitos humanos.

Diversas são as formas de controle e vigilância exercidas hoje sobre comunicações e dados pessoais na sociedade informacional. Estados através de seus órgãos de inteligência ou por meio de terceiros prestadores de serviço (provedores), bem como atores privados, como é o caso de empresas, definem algumas formas de vigilância, como acesso a e-mails e mensagens, identificação e receptação de telefones, bem como suas mensagens, utilização de softwares (malwares e spywares) para invasão de computadores pessoais e acesso a dados sensíveis.

O risco de, a partir dessas diversas formas novas de controle, haver violações de direitos de intimidade e liberdades de pensamento e expressão, segundo as declarações internacionais na ONU em consonância com o posicionamento do SIDH poderá ser mitigado no momento em que houver a superação de leis obsoletas que regulam a vigilância. Os standards legais inadequados aumentam o risco de os indivíduos de serem expostos, bem como não protegem os grupos minoritários da sociedade de eventuais perseguições advindas de um perfil traçado de seus metadados.

É, portanto, necessária a existência de leis nacionais que tragam autorização expressa sobre tecnologias e técnicas sobre vigilância, bem como definição de seu uso, prazo de controle, restrições explícitas, taxativas e claras, nos sentidos formal e material. Do contrário, os indivíduos não estarão aptos a prever ou saber sobre a aplicação dos sistemas de vigilância. Uma sociedade democrática necessita ter cidadãos informados, que se sintam seguros para que possam manifestar-se através das novas tecnologias, sem interferências indevidas.

Para tanto, foram eleitos pela sociedade civil, indústrias e especialistas na área, ${ }^{87}$ um conjunto de princípios que devem reger não só as legislações, como as práticas estatais e de empresas privadas com o escopo de diminuir o risco, cada vez mais elevado, de violações de direitos humanos através da vigilância de dados e informações pessoais. Legalidade, necessidade, fim legítimo e proporcionalidade são as principais bases que qualquer lei que regulamente sistemas de vigilância deve observar.

87 Necessary And Proportionate, Princípios Internacionais sobre a Aplicação Dos Direitos Humanos na Vigilância Das Comunicações, s/d. Disponível em: https: / / pt.necessaryandproportionate. org/text. Acesso em 05 jun 2015. 
Isso porque somente previsões legais e justificadas poderão dar ensejo à vigilância permitida de informações pessoais, e sua autorização deve ser concedida e fundamentada por autoridades jurisdicionais competentes e imparciais. O interesse legítimo deve corresponder a um interesse necessário a em uma sociedade democrática, bem como não podem ser realizados atos discriminatórios com base nos dados aferidos.

A notificação do usuário da decisão que autorizou a vigilância, bem como o estabelecimento de prazo para recurso e acesso ao material apresentado também constitui premissa relevante para as leis sobre vigilância. $\mathrm{O}$ atraso da notificação somente poderia ser aceito em casos em que esta tornaria inepto o propósito da vigilância. Além disso, outro princípio relevante é o da transparência, juntamente com o de escrutínio público, ou seja, mecanismos independentes para a fiscalização das atividades de controle, com vistas a garantir a responsabilidade e coibir eventuais arbitrariedades.

Desta feita, o sistema interamericano, em consonância com a jurisprudência ${ }^{88}$ e com princípios internacionais estabelece que os programas de vigilância devem ser desenhados e implementados respeitando os direitos humanos e fundamentais. Reconhece-se, portanto, que para que o risco não seja universalizado, são necessárias leis em consonância com os princípios de direitos humanos, extremamente claras, específicas e taxativas em relação aos sistemas de vigilância, bem como que haja demonstração da necessidade para o equilíbrio democrático da sociedade e da proporcionalidade das medidas tomadas, com invocação de que o interesse social na obtenção de informações privadas será maior que o eventual dano da vigilância dos dados e de comunicações.

\section{CONCLUSÃO}

Conforme destacado introdutoriamente, este estudo teve como intento verificar como o Sistema Interamericano de Proteção dos Direitos Huma-

88 Nesse sentido, inclusive, como forma de integridade do direito sobre o tema e de comunicação entre sistemas regionais, pertinente o destaque feito pelo dossiê do sistema interamericano de jurisprudências da Corte Europeia que afirma que a vigilância secreta debilita a democracia. Comissão Interamericana De Direitos Humanos (CIDH). Libertad de Expresión e Internet... cit. 
Esta revista forma parte del acervo de la Biblioteca Jurídica Virtual del Instituto de Investigaciones Jurídicas de la UNAM

nos trabalha com a dialética entre a liberdade e a vigilância possibilitadas pelas novas tecnologias da informação e comunicação, e quais saídas aponta para impedir a marcha rumo a uma sociedade de controle total. Como visto, até o momento não há julgados da Corte Interamericana de Direitos Humanos sobre o tema do acesso às novas tecnologias da informação e comunicação, tampouco acerca dos direitos de privacidade, intimidade e liberdade de expressão dos indivíduos na internet, relacionados aos riscos de vigilância e espionagem.

Mas, em 13 de dezembro de 2013, a Comissão Interamericana de Direitos Humanos (CIDH) aprovou a Relatoria Especial para a Liberdade de Expressão, documento que institui os princípios orientadores da liberdade de expressão na internet, dentre os quais figuram o acesso em igualdade de condições, o pluralismo, a não discriminação e a privacidade, todos eles estreitamente relacionados entre si.

Como visto, em consonância com os estudos sociológicos sobre internet e democracia, e também com as orientações dos organismos da ONU, o documento reconhece a centralidade da garantia do acesso à informação e a imprescindibilidade da disposição universal dos meios tecnológicos necessários ao acesso, com vistas ao plenipotencial desenvolvimento da liberdade humana na rede. Para tanto, estabelece a obrigação dos Estados erradicarem progressivamente a brecha digital a partir da implementação de medidas de universalização dos serviços de internet de qualidade e garantia de igualdade efetiva no acesso à informação, educação e cultura, bem como no exercício da cidadania.

Ao mesmo tempo, a Relatoria reconhece a existência de outra face da universalização do acesso, marcada pelos riscos de vigilância e controle total. Para a CIDH, a vigilância é uma realidade que pode infringir direitos humanos fundamentais, como a privacidade e a liberdade de pensamento e expressão. Todavia, considera que os riscos de violação de tais direitos podem ser minimizados por meio de normas jurídicas protetivas, consonantes com os princípios de direitos humanos e taxativas em relação aos sistemas de vigilância.

Nesse aspecto, o Sistema Interamericano de Direitos Humanos evita cair na compreensão fatalista - expressa por Jérémie Zimmermann e Julian Assange — de que a legislação e a política nada podem contra a vigilância e a dominação. Ao contrário, a Comissão Interamericana de Direitos Humanos, por meio da Relatoria Especial, afirma a necessidade e possibilidade 
de proteção da privacidade e intimidade por meio de legislações avançadas sobre a temática. Portanto, acredita na eficácia e autonomia do direito frente ao poder e aos interesses de outros sistemas sociais que se revelem contrários aos direitos humanos.

Por fim, cabe lembrar que, ao subscrever a Convenção Americana sobre Direitos Humanos, todos os Estados americanos assumem a obrigação internacional de respeitar os direitos ali previstos, adequar suas legislações internas aos preceitos da Convenção, bem como observar a jurisprudência dos órgãos que compõem o Sistema, por força do que estabelecem os $\operatorname{artigos} 1^{\circ}, 2^{\circ}$ e 62 da Convenção. Portanto, no que tange à proteção dos direitos humanos relacionados aos riscos de vigilância e controle por meio das tecnologias da informação, os Estados americanos estão obrigados a elaborar legislações protetivas específicas e adequadas aos princípios do direito internacional dos direitos humanos.

\section{REFERÊNCIAS}

Agaben, Giorgio, Estado de Exceção, trad. Iraci D. Poleti, 2. ed., São Paulo, Boitempo, 2004 (Estado de Sítio).

ARTIGO 19. Inclusão digital. Campanha banda larga é um direito seu. Artigo 19: Londres, s/d. Disponível em: http://artigo19.org/liberdadedigital/ category/inclusao-digital/. Acesso em: 02 jun. 2015.

Assange, Julian, Cypherpunks: liberdade e o futuro da internet, tradução Cristina Yamagami, São Paulo, Boitempo, 2013.

Biondi, Antonio et al. "Programa Nacional de Banda Larga no Brasil: características e desafios”, in SILVA, Sivaldo P. e BIONDI, Antonio (orgs.), Caminhos para a universalização da internet banda larga: experiências internacionais e desafios brasileiros, São Paulo, Intervozes, 2012.

CASTElls, Manuel, A Era da Informação: economia, sociedade e cultura, vol. 1 (Sociedade em Rede), São Paulo, Paz e Terra, 1999. , A galáxia da Internet: reflexões sobre a Internet, negócios e a sociedade, traduzido por Maria Luiza X. de A. Borges, Rio de Janeiro, Jorge Zahar Ed., 2003.

Comissão Interamericana de Direitos Humanos, Libertad de Expresión e Internet: Relatoria Especial para a Liberdade de Expressão, Dez. 2013. 
Disponível em: http://www.oas.org/es/cidh/expresion/temas/internet.asp. Acesso em 17 jun. 2015.

Corte Interamericana de Direitos Humanos, Caso Claude Reyes y otros vs. Chile. Sentencia de 19 de septiembre de 2006 (fondo, reparaciones y costas). Disponível em: http: / /www.corteidh.or.cr/docs/casos/articulos/ seriec_151_esp.pdf. Acesso em 9 mai. 2015.

Deleuze, Gilles, Conversações, tradução de Peter Pál Pelbert, São Paulo, Editora 34, 1992.

Delmas-Marty, Mireille, Résister, responsabiliser, anteciper, Paris, Seuil, 2013.

GIDDENS, Anthony, As consequências da modernidade, traduzido por Raul Fiker, São Paulo: Editora UNESP, 1991.

GonÇAlves, Maria Eduarda, Direito da informação: novos direitos e formas de regulação na sociedade da informação, Coimbra, Almedina, 2003.

LASH, Scott, Crítica de la información, tradução Horácio Pons, Buenos Aires: Amorrotu, 2005.

LÉvy, Pierre, Ciberdemocracia, Lisboa, Instituto Piaget, 2002.

, A Inteligência Coletiva: por uma antropologia do ciberespaço, 9.ed., São Paulo, Edições Loyola, 2014.

MatTelart, Armand, História das teorias da comunicação, São Paulo, Loyola, 1999.

Mazzuol, Valerio de Oliveira e TeIXeIRA, Gustavo de Faria Moreira, "O direito internacional do meio ambiente e o greening da convenção americana sobre direitos humanos", Revista Direito GV, São Paulo, no. 9(1), jan-jun. 2013, pp. 199-242.

MERLI, Daniel et al., "Exclusão digital no Brasil e em países emergentes: um panorama da primeira década do século XXI”, in SILVA, Sivaldo P. e BIONDI, Antonio (orgs.), Caminhos para a universalização da internet banda larga: experiências internacionais e desafios brasileiros, São Paulo, Intervozes, 2012.

Necessary And Proportionate, Princípios Internacionais sobre a Aplicação Dos Direitos Humanos na Vigilância Das Comunicações, s/d. Disponível em: https: / / pt.necessaryandproportionate.org/text. Acesso em 05 jun 2015.

OrganizaÇÃo Das NaÇÕes Unidas (ONU), Relatório do Relator Especial sobre Promoção e Proteção do Direito à Liberdade de Expressão, Frank la Rue, da ONU (A/HRC/23/40), 2013. Disponível em: http://ap.ohchr.org/ documents /dpage_s.aspx?m=85. Acesso em 01 jun 2015. 
e Organização Dos Estados Americanos. Declaração conjunta sobre programas de vigilância e seus impactos sobre a liberdade de expressão. 2013.Disponível em: http://www.oas.org/pt/cidh/expressao/showarticle. asp?artID =926\&IID =4. Acesso 03 jun 2015 .

PÉREZ LuÑo, Antonio-Enrique, Ciberciudadani@o ciudadani@.com?, Barcelona, Gedisa, 2004.

Possebon, Samuel, "Prefácio" in Silva, Sivaldo P. e BiOndi, Antonio (orgs.), Caminhos para a universalização da internet banda larga: experiências internacionais e desafios brasileiros, São Paulo, Intervozes, 2012.

RAMONET, Ignacio, ¡Nos han robado una esperanza!, s/d. Disponível em: http://pendientedemigracion.ucm.es/info/uepei/noshanrobado.html. Acesso em 9 mai. 2015.

Rifkin, Jeremy, A Era do Acesso, traduzido por Maria Lucia G. L. Rosa, São Paulo, Makron Books, 2001.

Rosa, Artmut, Aliénation et acceleration, Paris, Découvert, 2012.

SAntos, Laymert Garcia, Politizar as novas tecnologias. O impacto sociotécnico da informação digital e genética, São Paulo, Ed. 34, 2003.

SANTOS, Milton, Técnica, Espaço, Tempo: globalização e meio técnico-científicoinformacional, 5a. ed., São Paulo, Editora da Universidade de São Paulo, 2013.

Senado Federal, Relatório de Avaliação do Programa Nacional de Banda Larga (PNBL), Dez. 2014. Disponível em: http://www.senado.gov.br/noticias/es peciais/politicas-publicas-pnbl/. Acesso em 17 jun. 2015.

Silva, Sivaldo P. e BIONDI, Antonio, "Políticas públicas e regulação do acesso à Internet banda larga: diretrizes para o caso brasileiro sob a luz das experiências internacionais", in SILVA, Sivaldo P. e BIONDI, Antonio (orgs.), Caminhos para a universalização da internet banda larga: experiências internacionais e desafios brasileiros, São Paulo, Intervozes, 2012.

VAidhyanathan, Siva, A googlelização de tudo: e por que devemos nos preocupar. A ameaça do controle total da informação por meio da maior e mais bem sucedida empresa do mundo virtual, São Paulo, Editora Cultrix, 2011.

VAlEnTE, Jonas C. L., "Regulação do Acesso à Internet no Mundo: modelos, direitos e desafios”, in SILVA, Sivaldo P. e BIONDI, Antonio (orgs.), Caminhos para a universalização da internet banda larga: experiências internacionais e desafios brasileiros, São Paulo, Intervozes, 2012.

VIRILIO, Paul, La bombe informatique, Paris, Galilée, 1998. 
Esta revista forma parte del acervo de la Biblioteca Jurídica Virtual del Instituto de Investigaciones Jurídicas de la UNAM www.juridicas.unam.mx

VOLKMER, André, “A democracia na era digital”, in Instituto de Estudos Empresariais, Liberdade na era digital, Porto Alegre, IEE, 2011.

WORLD BANK, Information and Communications for Development 2009: Extending Reach and Increasing Impact, Washington DC, World Bank, 2009. 